\title{
A case of thyrotoxic periodic paralysis as initial manifestation of Graves' disease in a 16-year-old Korean adolescent
}

\author{
Se Yong Jung, MD', \\ Kyung Chul Song, MD', \\ Jae II Shin, MD', \\ Hyun Wook Chae, MD', \\ Ho-Seong Kim, MD, PhD', \\ Ah Reum Kwon, MD ${ }^{1}$ \\ Departments of ${ }^{1}$ Pediatric \\ Endocrinology and ${ }^{2}$ Pediatric \\ Neprhology, Yonsei University College \\ of Medicine, Seoul, Korea
}

\begin{abstract}
Thyrotoxic periodic paralysis (TPP) is a rare complication of hyperthyroidism, with recurrent muscle paralysis and hypokalemia that are caused by an intracellular shift of potassium. TPP is relatively common in Asian males, but is extremely rare in children and adolescents, even for those of Asian descent. We describe a 16-year-old Korean adolescent presenting with a two-week history of episodic leg weakness in the morning. He showed sinus tachycardia, lower leg weakness, and hypokalemia. Thyroid function test showed hyperthyroidism, and thyroid ultrasonography revealed a diffuse enlarged thyroid with increased vascularity, consistent with Graves' disease. He was treated with $\beta$-adrenergic blocker and antithyroid drugs. He has been symptom free for one year, as his hyperthyroidism has been controlled well with antithyroid drugs. TPP should be considered in children and adolescents with acute paralysis of the lower extremities and hypokalemia.
\end{abstract}

Keywords: Thyrotoxic periodic paralysis, Graves' disease, Adolescent, Korean

\section{Introduction}

Thyrotoxic periodic paralysis (TPP) consists of episodes of muscle paralysis due to the hypokalemia that is associated with hyperthyroidism ${ }^{1)}$. Even though TPP mainly affects Asian populations with an incidence of approximately only $2 \%$ in hyperthyroidism patients ${ }^{2)}$, it is a very rare disease in children and adolescents in Asian as well as other ethnic groups. Paralysis of TPP is characterized by acute, reversible attacks of flaccid paralysis affecting the proximal muscles more severely than the distal muscles ${ }^{3)}$. The extent of paralysis varies from mild weakness to complete flaccid paralysis, and although spontaneous resolution of the paralysis occurs in from a few hours to two days, cases of fatal ventricular arrhythmia ${ }^{4)}$ and respiratory failure have been reported. Therefore, early recognition and prompt treatment is essential for avoiding such fatal complications. However, the diagnosis of TPP in children is challenging, because it is very rare in children and adolescents, and paralysis is occasionally the first and sole signs of TPP. We report on a Korean adolescent who presented with TPP as the initial manifestation of Graves' disease.

\section{Case report}

A 16-year-old Korean male presented with two episodes of lower leg paralysis in the morning for two weeks. The first episode was a sudden onset of complete paralysis below distal thigh, and he had no other symptoms except leg paralysis. At a local clinic, physical examination revealed symmetric hyporeflexia in both lower extremities. Laboratory analysis revealed mild hypokalemia as below: $\mathrm{Na}^{+}, 146 \mathrm{mmol} / \mathrm{L} ; \mathrm{K}^{+}, 2.7 \mathrm{mmol} / \mathrm{L} ; \mathrm{Cl}^{-}, 110 \mathrm{mmol} / \mathrm{L}$; $\mathrm{tCO}_{2}, 25 \mathrm{mmol} / \mathrm{L}$ without abnormality of blood gas analysis. Electrocardiogram showed only

Tel: $+82-2-2228-8203$

Fax: $+82-2-393-9118$

E-mail: arema@yuhs.ac 
sinus tachycardia without atrioventricular block or prominent $\mathrm{U}$ wave. However, further evaluation for hypokalemia was not taken, even though there was a suggestion of hypokalemic paralysis, and the patient was just advised to eat an adequate dietary supplement of potassium rich food without any medication by the local clinic. After two weeks, a second episode of leg weakness occurred after morning meal. The muscle weakness was initially subtle but progressed in paralysis below knee and lasted for 6 hours. Thus, he was referred to our hospital. However, the patient visited our clinic the next day, when the paralysis had already subsided.

There was no past history or family history of neuromuscular disease and endocrinologic disease, except for his aunt's hypothyroidism. His appearance was reasonably healthy. His height was $168 \mathrm{~cm}$, his weight was $60 \mathrm{~kg}$, and his body mass index was $21.2 \mathrm{~kg} / \mathrm{m}^{2}$. His blood pressure was $110 / 80$ $\mathrm{mmHg}$, his respiratory rate was 18 breaths/min, and his body temperature was $36.8^{\circ} \mathrm{C}$. He had mild tachycardia with a heart rate of $100-110$ beats $/ \mathrm{min}$, but he had no palpitations. Neurological examination findings, including deep tendon reflex and cerebellar function test, were normal. The laboratory findings showed normal complete blood cell counts, normal electrolytes as below: $\mathrm{Na}^{+}, 140 \mathrm{mmol} / \mathrm{L} ; \mathrm{K}^{+}, 4.4 \mathrm{mmol} / \mathrm{L} \mathrm{Cl}^{-}$, $104 \mathrm{mmol} / \mathrm{L} ; \mathrm{tCO}_{2}, 24 \mathrm{mmol} / \mathrm{L}$. The laboratory findings also showed his normal liver, kidney and cardiac functions. His urine $\mathrm{K}^{+}$excretion rate was normally low as 0.96 of urine $\mathrm{K}^{+} /$ Cr ratio (range, $0-2$ ). There were no abnormal laboratory findings to suggest adrenal hormone excess or primary hyperaldosteronism: adrenocorticotropic hormone, $40.11 \mathrm{pg} /$ $\mathrm{mL}$ (range, 3.5-13.2 pg/mL); cortisol, $8.7 \mu \mathrm{g} / \mathrm{dL}$ (range, 5.0-23.0 $\mu \mathrm{g} / \mathrm{dL}$ ); 17 hydroxyprogesterone, $2.68 \mathrm{ng} / \mathrm{mL}$ (range, $0.6-3.42$ $\mathrm{ng} / \mathrm{mL}$ ); aldosterone, $180.29 \mathrm{pg} / \mathrm{mL}$ (range, $38.9-306.8 \mathrm{pg} / \mathrm{mL}$ ); renin, $6.13 \mathrm{ng} / \mathrm{mL} / \mathrm{hr}$ (range, $1.31-3.95 \mathrm{ng} / \mathrm{mL} / \mathrm{hr}$ ); epinephrine, $0.030 \mathrm{ng} / \mathrm{mL}$ (range, $0-0.30 \mathrm{ng} / \mathrm{mL}$ ); norepinephrine, $0.087 \mathrm{ng} /$ $\mathrm{mL}$ (range, $0-0.80 \mathrm{ng} / \mathrm{mL}$ ). Thyroid function test (TFT) revealed a hyperthyroidism: serum free thyroxine (fT4), $2.10 \mathrm{ng} / \mathrm{dL}$ (range, $0.70-1.48 \mathrm{ng} / \mathrm{dL}$ ); triiodothyronine (T3), $2.95 \mathrm{ng} / \mathrm{mL}$ (range, $0.58-1.59 \mathrm{ng} / \mathrm{mL}$ ); thyroid-stimulating hormone (TSH), $<0.025 \mathrm{mU} / \mathrm{L}$ (range, $0.35-4.94 \mathrm{mU} / \mathrm{L}$ ). Thus, he was diagnosed as having hypokalemic paralysis due to hyperthyroidim. Serum TSH receptor antibodies were high at $6.05 \mathrm{IU} / \mathrm{L}$ (range, $0-1.75 \mathrm{IU} / \mathrm{L}$ ), thyroid stimulating antibody was positive, and

Table 1. Thyroid function test and electrolytes during follow-up

\begin{tabular}{|c|c|c|c|c|c|c|c|c|}
\hline Variable & 1st Paralysis & $\begin{array}{l}\text { At diagnosis } \\
\text { 2nd paralysis }\end{array}$ & 2 Weeks & 1 Months & 2 Months & 4 Months & 6 Months & 9 Months \\
\hline Free T4 (ng/dL) & $\mathrm{N} / \mathrm{A}$ & 2.10 & 2.97 & 2.14 & 1.57 & 1.20 & 1.31 & 1.07 \\
\hline $\mathrm{T} 3(\mathrm{ng} / \mathrm{mL})$ & N/A & 2.95 & $>8.00$ & 3.57 & 1.82 & 1.23 & 1.24 & 1.14 \\
\hline TSH (ulU/mL) & $\mathrm{N} / \mathrm{A}$ & $<0.025$ & $<0.025$ & $<0.025$ & $<0.025$ & $<0.025$ & $<0.025$ & 0.230 \\
\hline $\mathrm{Na}^{+}(\mathrm{mmol} / \mathrm{L})$ & 146 & 139 & 140 & 143 & 142 & 140 & 140 & 142 \\
\hline $\mathrm{K}^{+}(\mathrm{mmol} / \mathrm{L})$ & 2.7 & 4.6 & 4.4 & 4.2 & 3.8 & 4.3 & 4.1 & 4.2 \\
\hline $\mathrm{Cl}^{-}(\mathrm{mmol} / \mathrm{L})$ & 110 & 102 & 104 & 106 & 103 & 105 & 104 & 105 \\
\hline $\mathrm{tCO}_{2}(\mathrm{mmol} / \mathrm{L})$ & 25 & 27 & 24 & 24 & 27 & 24 & 26 & 25 \\
\hline Muscle weakness & $\begin{array}{l}\text { Lower leg paralysis } \\
\text { for } 12 \mathrm{hr}\end{array}$ & $\begin{array}{l}\text { Lower leg paralysis } \\
\text { for } 6 \mathrm{hr}\end{array}$ & None & None & None & None & None & None \\
\hline Methimazole & None & 5 mg q.d. & 10 mg b.i.d & 10 mg b.i.d & 10 mg b.i.d & 10 mg b.i.d & $7.5 \mathrm{mg}$ b.i.d & $7.5 \mathrm{mg}$ b.i.d \\
\hline Propranolol & None & $10 \mathrm{mg}$ t.i.d & $10 \mathrm{mg}$ t.i.d & 10 mg t.i.d & Discontinued & & & \\
\hline
\end{tabular}

T4, thyroxine; T3, triiodothyronine; N/A, not available; TSH, thyroid-stimulating hormone; q.d., once a day; b.i.d., twice a day; t.i.d., three times a day.

Table 2. Characteristics of previously reported adolescent TPP patients

\begin{tabular}{|c|c|c|c|c|c|c|c|c|c|c|c|}
\hline & Sex & Age (yr) & Race & Etiology & $\begin{array}{l}\text { Free T4 } \\
\text { (ng/dL) }\end{array}$ & $\begin{array}{c}\mathrm{T} 3 \\
\text { (ng/mL) }\end{array}$ & $\begin{array}{c}\text { TSH } \\
(\mu \mathrm{IU} / \mathrm{mL})\end{array}$ & $\begin{array}{c}\mathrm{K}^{+} \\
(\mathrm{mmol} / \mathrm{L})\end{array}$ & $\begin{array}{l}\text { Definitive } \\
\text { treatment }\end{array}$ & Remark & References \\
\hline Patient 1 & M & 16 & Chinese & Graves' disease & 1.64 & 4.04 & $<0.03$ & 2.0 & $\begin{array}{c}\text { Propranolol + MMI } \\
\longrightarrow \mathrm{Rl}\end{array}$ & & 5 \\
\hline Patient 2 & M & 14 & Chinese & Graves' disease & 2.55 & 8.40 & $<0.03$ & 2.2 & $\begin{array}{c}\text { Propranolol + } \\
\text { Carbimazole }\end{array}$ & $\begin{array}{l}\text { Rebound } \\
\text { hyperkalemiaa) }\end{array}$ & 6 \\
\hline Patient 3 & $F$ & 14 & Korean & Graves' disease & 3.80 & 1.83 & $<0.03$ & 2.3 & Propranolol + MMI & & 7 \\
\hline Patient 4 & M & 16 & Korean & Graves' disease & 1.87 & 1.80 & 0.09 & 2.5 & $\mathrm{MMI}$ & $\begin{array}{l}\text { Three recurrent } \\
\text { TPP despite } \\
\text { treatment }\end{array}$ & 8 \\
\hline
\end{tabular}

TPP, thyrotoxic periodic paralysis; T4, thyroxine; T3, triiodothyronine; TSH, thyroid-stimulating hormone; MMI, methimazole; RI, radioactive iodine

${ }^{a}$ Rebound hyperkalemia was occurred in patient 2 after intravenous potassium replacement. The potassium level was high as $7 \mathrm{mmol} / \mathrm{L}$,

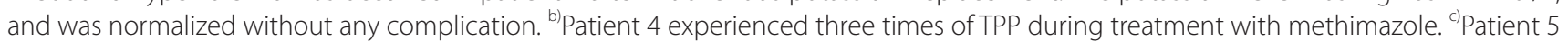
is presenting case in this article. The potassium level and thyroid function test of patient 5 was not examined simultaneously. 
thyroid ultrasonography revealed diffuse enlarged thyroid and increased vascularity. These findings were consistent with Graves' disease as etiology of his hyperthyroidism. He was initially treated with lower dose of an antithyroid drug (methimazole $5 \mathrm{mg}$ once daily) than usual, since his thyrotoxic symptoms and signs were absent, and his level of serum fT4 was not prominent. In addition, a $\beta$-adrenergic blocker (propranolol) was simultaneously used for preventing the paralysis. After two weeks, a follow-up TFT revealed aggravated hyperthyroidism, and he was treated with increased dose of antithyroid drugs. After two months, since his heart rate and blood pressure were stable and he had no symptoms of palpitations, $\beta$-blockers were discontinued successfully. No paralysis has occurred for one year, as hyperthyroidism can be well controlled with antithyroid drugs (Table 1).

\section{Discussion}

TPP is an uncommon complication of hyperthyroidism, with recurrent muscle paralysis and hypokalemia. Although TPP is rare, it is more prevalent in Asians than other ethnic groups. The incidence is approximately $2 \%$ in Asian hyperthyroidism patients ${ }^{2}$, and $0.1 \%-0.2 \%$ in North America $^{3)}$, but it has been increasingly reported in nonAsians. Regarding age, TPP is most prevalent in 20-40 years old, and is a very rare in children and adolescents. There are only few reported cases in pediatric patient $\mathrm{s}^{5-8)}$, even in Asian populations, and the exact incidence in the pediatric population has yet to be established. Our presenting case may be the third reported case of a pediatric Korean TPP patient as far as we know. In review of previous reported pediatric TPP patients (Table 2), all of five were Asian patients with Graves disease. Only one was female patient which reflected the male predominance of TPP.

The pathogenesis of TPP remains uncertain; however, it is well known that the hypokalemia in TPP is caused by the intracellular shift of potassium rather than pure potassium depletion in the body. The intracellular shift of potassium is primarily regulated with $\mathrm{Na}^{+}-\mathrm{K}^{+}$ adenosine triphosphatase (ATPase) pump activity in cell membranes, which exchanges $\mathrm{Na}^{+}$(out of the cell) for $\mathrm{K}^{+}$(into the cell). Therefore, the increased number or enhanced activity of $\mathrm{Na}^{+}-\mathrm{K}^{+}$ATPase could induce hypokalemia leading to paralysis. Thyroid hormones, $\beta$-adrenergic catecholamine, and insulin are known activators of $\mathrm{Na}^{+}-\mathrm{K}^{+}$ATPase. Thyroid hormones increase both the activity of $\mathrm{Na}^{+}-\mathrm{K}^{+}$ATPase and the number of messenger RNA and proteins of $\mathrm{Na}^{+}-\mathrm{K}^{+}$ATPase via transcriptional and posttranscriptional mechanisms, leading to an increased number of $\mathrm{Na}^{+}-\mathrm{K}^{+}$ATPase ${ }^{9)}$.
Previous experimental studies have shown that the $\mathrm{Na}^{+}-\mathrm{K}^{+}$ATPase activity is higher in thyrotoxic patients with TPP than in thyrotoxic patients without paralysis ${ }^{10)}$, and the number of $\mathrm{Na}^{+}-\mathrm{K}^{+}$ATPase is correlated with the serum thyroid levels ${ }^{11)}$. In addition, excessive thyroid hormone is essential in TPP, since paralysis typically does not occur once the patient achieves euthyroid status. Catecholamines also increase the $\mathrm{Na}^{+}-\mathrm{K}^{+}$ATPase activity via $\beta$-adrenergic receptors and through the activation of cyclic adeonosine monophosphate. It could explain why nonselective $\beta$-adrenergic blockers can abort or prevent paralytic attacks ${ }^{12)}$, and why stressful conditions such as cold exposure, infection, emotional stress, and trauma can promote TPP. Furthermore, excessive thyroid hormone increases both number and activity of $\beta$-adrenergic receptors, which further increase the $\mathrm{Na}^{+}-\mathrm{K}^{+}$ATPase activity, which becomes even worse in TPP. $\mathrm{Na}^{+}-\mathrm{K}^{+}$ATPase activity is also increased by androgen ${ }^{13)}$, therefore, TPP occurs predominantly in men, despite hyperthyroidism being more frequent in women. In the rest, insulin is another well-known activator of $\mathrm{Na}^{+}-\mathrm{K}^{+}$ATPase, which would explain why a high carbohydrate meal could promote TPP.

Graves' disease is the most common cause of TPP. Other causes of thyrotoxicosis include toxic nodular goiter, subacute thyroiditis, toxic adenoma, and TSHsecreting pituitary tumor, which could induce paralysis ${ }^{14)}$. Usually, a diagnosis of hyperthyroidism is not difficult, because of its typical symptoms and signs such as weight loss, heat intolerance, palpitations, and exophthalmos. However, in TPP patients, the clinical symptoms and signs of hyperthyroidism may be subtle, thus TPP is often overlooked in hypokalemic paralysis. A recent study in Taiwan revealed that only $17 \%$ of TPP patients have overt symptoms and signs of thyrtoxicosis ${ }^{15)}$, and some reports have shown that paralysis is the initial and sole sign of thyrotoxicosis ${ }^{16)}$ as in our case. Thus, recognizing the pattern of paralysis is important. Unfortunately, TPP is usually indistinguishable to other hypokalemic paralysis symptoms. The extent of paralysis is usually correlated with serum potassium level, although rare cases of normokalemic TPP had been reported ${ }^{17}$.

The onset of TPP is usually sudden; weakness begins in the lower proximal extremities, and can progress to flaccid quadriplegia. Deep tendon reflexes are usually decreased, but sensory function is usually spared. Most attacks occur during rests after exercise, not during exercise. It could be explained that exercise releases potassium from the skeletal muscles, but rest enhances the influx of potassium. These findings are consistent with other hypokalemic 
paralysis as well as those in TPP. Typically, TPP patients do not have persistent neuromuscular symptoms between attacks, although these findings are not limited to TPP.

Due to the subtlety of thyrotoxicosis and indistinguishable features of paralysis from other etiologies, the differential diagnosis of TPP in hypokalemic paralysis is sometimes difficult. However, as Lin et al. ${ }^{18)}$ had suggested, patients presenting with hypokalemic paralysis could be simply divided into two groups; hypokalemic paralysis due to the depletion of potassium in the body, or due to the intracellular shifting of $\mathrm{K}^{+}$. The urinary $\mathrm{K}^{+}$excretion rate and the blood acid-base status may be helpful for a differential diagnosis. High $\mathrm{K}^{+}$excretion and an abnormal acid-base suggest the mechanism is the depletion of potassium in the body. In these groups, metabolic alkalosis suggests that the etiology is renal tubular acidosis, toluene abuse, or diarrhea, while metabolic acidosis suggests mineralocorticoid excess, vomiting, use of diuretics, Gitelman's syndrome, or Bartter's syndrome as an etiology. While low urinary $\mathrm{K}^{+}$excretion and normal acid base, as in our case, suggest that the mechanism is the intracellular shifting of $\mathrm{K}^{+}$including TPP, as in familial periodic paralysis, barium poisoning, and idiopathic periodic paralysis. In brief, taking a detailed history, including family history, drug history, and laboratory examination including TFTs, blood gas analysis, and urinary analysis for potassium excretion rate are essential to the differential diagnosis. In the presented case, the patient showed only bilateral lower leg paralysis accompanying hypokalemia; thus, the etiology of hypokalemic paralysis should be evaluated, but it was overlooked at the local clinic. While he showed normal acid-base blood gas study, low urinary potassium excretion and hyperthyroidism, we could assess that his hypokalemia was induced by the intracellular shifting of potassium due to his hyperthyroidism. Further evaluation for hyperthyroidism revealed that he had Graves' disease presenting with paralysis as his first and only manifestation.

Treatment of TPP requires two steps, management of hypokalemia, and the maintenance of euthyroid status. Potassium replacement is necessary for the avoidance of fatal arrhythmia and for the rapid recovery from muscle weakness. However, hypokalemia is not caused by a total body depletion of potassium, and so cautious potassium replacement is essential to avoid rebound hyperkalemia on that account ${ }^{19)}$. Besides potassium replacement, nonselective $\beta$-blockers are used for the prevention of recurrent paralysis based on the pathogenesis of hyperadrenergic activity during a thyrotoxic period. In review of preivous pediatric TPP, only one patient, who did not receive nonselective $\beta$-blockers, experienced recurrent paralysis. Recently, some cases of TPP were reversed with highdose oral propranolol $(3 \mathrm{mg} / \mathrm{kg})$ without potassium replacement to avoid the rebound hyperkalemia ${ }^{20)}$. Regular potassium supplement is usually not required, as in our case. As paralysis does not occur once the patient has achieved euthyroid status, $\beta$-adrenergic blockers are usually used with other treatments during that period. Maintenance of euthyroidism is the definitive treatment of TPP. Antithyroid drugs are the mainstay of treatment of hyperthyroidism, although treatment should be individualized for a patient. Four of five pediatric TPP cases including our case were treated with antithyroid drugs, while only one patient received radioactive iodine therapy after antithyroid drug treatment.

In conclusion, pediatricians should consider TPP as one of the differential diagnosis of muscle weakness or acute paralysis of the low extremities with hypokalemia in children and adolescents. TPP could be diagnosed by taking a detailed history and laboratory findings including blood gas analysis, urine potassium excretion ratio, and TFT.

\section{Conflict of interest}

No potential conflict of interest relevant to this article was reported.

\section{References}

1. Ober KP. Thyrotoxic periodic paralysis in the United States. Report of 7 cases and review of the literature. Medicine (Baltimore) 1992;71:109-20.

2. McFadzean AJ, Yeung R. Periodic paralysis complicating thyrotoxicosis in Chinese. Br Med J 1967;1:451-5.

3. Kelley DE, Gharib H, Kennedy FP, Duda RJ Jr, McManis PG. Thyrotoxic periodic paralysis. Report of 10 cases and review of electromyographic findings. Arch Intern Med 1989;149:2597-600.

4. Lee JI, Sohn TS, Son HS, Oh SJ, Kwon HS, Chang SA, et al. Thyrotoxic periodic paralysis presenting as polymorphic ventricular tachycardia induced by painless thyroiditis. Thyroid 2009;19:1433-4.

5. Miller JD, Quillian W, Cleveland WW. Nonfamilial hypokalemic periodic paralysis and thyrotoxicosis in a 16-year-old male. Pediatrics 1997;100(3 Pt 1):412.

6. Wong GW, Leung TF, Lo AF, Ahuja AT, Cheng PS. Thyrotoxic periodic paralysis in a 14-year-old boy. Eur J Pediatr 2000;159:934.

7. Oh KW, Jeong JY, Kim JS. A case of thyrotoxic periodic paralysis in adolescent with Graves' disease. J Korean Soc 
Pediatr Endocrinol 2011;16:196-200.

8. Ahn MB, Jung YJ, Lee MH, Cho WK, Suh BK. A case of thyrotoxic periodic paralysis in a 16-year-old adolescent. Ann Pediatr Endocrinol Metab 2012;17:117-21.

9. Azuma KK, Hensley CB, Tang MJ, McDonough AA. Thyroid hormone specifically regulates skeletal muscle $\mathrm{Na}(+)-\mathrm{K}(+)$-ATPase alpha 2- and beta 2-isoforms. Am J Physiol 1993;265(3 Pt 1):C680-7.

10. Chan A, Shinde R, Chow CC, Cockram CS, Swaminathan R. In vivo and in vitro sodium pump activity in subjects with thyrotoxic periodic paralysis. BMJ 1991;303:1096-9.

11. Kjeldsen K, Norgaard A, Gotzsche CO, Thomassen A, Clausen T. Effect of thyroid function on number of $\mathrm{Na}-\mathrm{K}$ pumps in human skeletal muscle. Lancet 1984;2:8-10.

12. Lin SH, Lin YF. Propranolol rapidly reverses paralysis, hypokalemia, and hypophosphatemia in thyrotoxic periodic paralysis. Am J Kidney Dis 2001;37:620-3.

13. Guerra M, Rodriguez del Castillo A, Battaner E, Mas M. Androgens stimulate preoptic area $\mathrm{Na}^{+}, \mathrm{K}^{+}$-ATPase activity in male rats. Neurosci Lett 1987;78:97-100.

14. Kung AW. Clinical review: thyrotoxic periodic paralysis: a diagnostic challenge. J Clin Endocrinol Metab 2006;91: 2490-5.

15. Chang CC, Cheng CJ, Sung CC, Chiueh TS, Lee CH, Chau T, et al. A 10-year analysis of thyrotoxic periodic paralysis in 135 patients: focus on symptomatology and precipitants. Eur J Endocrinol 2013;169:529-36.

16. Trifanescu RA, Danciulescu Miulescu R, Carsote M, Poiana C. Hypokalemic periodic paralysis as first sign of thyrotoxicosis. J Med Life 2013;6:72-5.

17. Valizadeh N, Zarrin S. A 32-year-old man with normokalemic thyrotoxic periodic paralysis. Malays J Med Sci 2013; 20:81-3.

18. Lin SH, Chiu JS, Hsu CW, Chau T. A simple and rapid approach to hypokalemic paralysis. Am J Emerg Med 2003;21:487-91.

19. Ahmed I, Chilimuri SS. Fatal dysrhythmia following potassium replacement for hypokalemic periodic paralysis. West J Emerg Med 2010;11:57-9.

20. Cope TE, Samaraweera AP, Burn DJ. Thyrotoxic periodic paralysis: correct hypokalemia with caution. J Emerg Med 2013;45:338-40 